\title{
A Method for Calculating Elliptic Gear Transmission Efficiency Based on Transmission Experiment
}

\author{
Changbin Dong 1 - Yongping Liu ${ }^{1}$ - Gang Zhao ${ }^{2}$ \\ ${ }^{1}$ Lanzhou University of Technology, School of Mechanical and Electric Engineering, China \\ ${ }^{2}$ Hubei Key Laboratory of Mechanical Transmission and Manufacturing Engineering, China
}

Transmission efficiency is an important index to evaluate the transmission performance and energy consumption of gear transmission systems. To analyse the transmission efficiency of elliptic gears, the load torque fluctuation model of elliptic gear is established to analyse the influence of load torque of an elliptic gear transmission system on the torque of input and output. The torque data of input and output under different working conditions are obtained by conducting an elliptic gear transmission test. Finally, the transmission efficiency of the elliptic gear pair is obtained through the torque measurement data of the elliptic gear transmission test, and its variation law under different working conditions is analysed. The results show that the transmission efficiency of the elliptic gear transmission system changes constantly and presents an increasing trend with the increase of load torque and a decreasing trend with the increase of speed.

Keywords: elliptic gear, transmission test, load fluctuation, torque, transmission efficiency

\author{
Highlights \\ - The torque fluctuation calculation model of an elliptic gear is analysed and established. \\ - $\quad$ The elliptic gear transmission test rig is built, which can be used to obtain the corresponding dynamic data. \\ - The dynamic transmission efficiency of an elliptic gear pair is calculated and obtained, and the influence of various operating \\ parameters on the instantaneous transmission efficiency of the system is analysed.
}

\section{INTRODUCTION}

With the development of mechanical products towards complexity and diversification, the demand for highperformance non-uniform transmission mechanisms increases day by day. The transmission mechanism represented by non-circular gear, which can achieve an accurate and stable speed ratio, shows unique advantages in improving equipment performance and realizing specific transmission requirements [1] and [2]. As a new type of gear transmission, the elliptic gear is mainly used to transmit the non-uniform motion between two shafts, and to realize the nonlinear relationship between the rotation angles of driving and driven parts [3] and [4]. The non-circular gear transmission system represented by elliptic gear has a strong bearing capacity, a compact structure, and a variable ratio transmission. It is mainly used in low speed and high torque occasions, such as rotary vane engines, hydraulic pumps, hydraulic motors, printing presses, packaging machines, textile equipment, spacecraft frequency converters, tank fire control systems [5] and [6], continuously variable transmissions (CVT) [7], etc. Considering the expansion of its applications and the key role and special requirements in the transmission, it is meaningful to carry out in-depth research on the transmission efficiency of the elliptic gear transmission system.
Many research results have been accumulated for the transmission efficiency analysis method of gear transmission systems. Diez-Ibarbia et al. [8] combined the tooth surface friction coefficient and transmission efficiency, analysed the influence of the selection of friction coefficient on the transmission efficiency of modified spur gears. Wang et al. carried out a detailed study on the transmission efficiency of gear transmission systems. They combined tooth surface friction with power loss and tooth surface elastohydrodynamic lubrication [9] and proposed a calculation method of sliding friction loss of involute helical gear pair under load [10], considering assembly error, machining error, deformation, and other factors. On this basis, the friction power loss and transmission efficiency of the gear transmission system under different working conditions and design parameters are analysed [11] to [12], and the relevant data are obtained by building an experimental platform, which finally verifies the rationality of the proposed method [13] to [14]. Petry-Johnson et al. [15] obtained the transmission efficiency of the system under the condition of high speed and variable torque by building a gear transmission test and analysed the changing trend of the meshing efficiency of the gear transmission system and the total efficiency of the gearbox under the condition of different speed and load torque. Xu et al. [16] proposed and established the calculation model of friction-related mechanical 
efficiency loss of parallel shaft gear pair on the basis of comprehensively considering gear load distribution model, friction model and mechanical efficiency formula. Through gear transmission testing, the effects of geometric parameters, tooth profile modification, working conditions, surface finish, and lubricant performance on mechanical efficiency loss were analysed. Based on the elastohydrodynamic lubrication model, Li and Kahraman [17] proposed a model to predict the load-related power loss of spur gear pair. The instantaneous rolling and sliding shear in lubricating oil are determined by transient pressure distribution and oil film thickness distribution, so as to determine the mechanical power loss of gear meshing. $\mathrm{Li}$ et al. [18] determined the calculation formula of the meshing efficiency of the conical involute gear based on the piecewise equivalent method and analysed the influence of different gear parameters on the contact line length, unit load and meshing efficiency in the meshing period. Liu et al. [1] and [2] constructed a non-uniform end face movable tooth transmission mechanism by combining the end face movable tooth mechanism and non-circular gear pairs and analysed the influence of tooth surface sliding friction on the transmission efficiency through simulation. Liu et al. [19] analysed the influence of time-varying meshing angle of non-circular gear pair on rolling rate loss caused by sliding friction and rolling friction by establishing a mathematical model of meshing efficiency of non-circular gear under elastohydrodynamic lubrication.

Although the above research results have irreplaceable guiding significance for the analysis of transmission efficiency of the elliptic gear transmission system, most of the analysis of transmission efficiency of non-circular gear is only theoretical calculation without systematic experimental analysis. In contrast, the experimental analysis can better reflect the authenticity and has more guiding significance. Therefore, this paper first analyses the load fluctuation of the elliptic gear transmission system and extracts the torque data of the input and output ends by building the elliptic gear transmission test-bed; it then calculates and obtains the instantaneous transmission efficiency of the elliptic gear transmission system.

\section{CALCULATION MODEL OF TRANSMISSION EFFICIENCY OF ELLIPTIC GEAR}

Because of the variable ratio transmission characteristics of elliptic gear pairs, their instantaneous transmission efficiency is always changing. The transmission efficiency of a gear pair can reflect its load-carrying capacity and power loss, especially for elliptic gears, which are suitable for low-speed and high torque conditions. Therefore, it is of great significance to analyse its instantaneous transmission efficiency. In general, the transmission efficiency of elliptic gear system is defined as:

$$
\eta=\frac{T_{2}}{T_{1} i_{12}} \times 100, \quad[\%]
$$

where $T_{1}$ represents the arithmetic mean value of input torque, $T_{2}$ represents the arithmetic mean value of the output torque, and $i_{12}$ represents the transmission ratio of elliptic gear pair.

\subsection{Pitch Curve of Elliptic Gear}

Fig. 1 shows the pitch curve of elliptic gear. The centre distance of the elliptic gear pair is $a$. The rotation angles of driving and driven gears are $\theta_{1}$ and $\theta_{2}$, respectively. In the initial position, $\theta_{1}=\theta_{2}=0$. The pitch curve equations of the driving and driven gears are as follows:

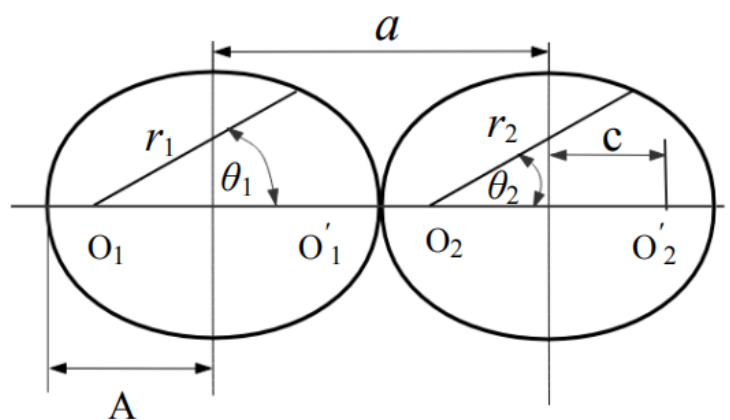

Fig. 1. Schematic diagram of elliptic gear pitch curve

$$
\begin{aligned}
& r_{1}=\frac{A\left(1-e_{1}^{2}\right)}{1-e_{1} \cos \left(\theta_{1}\right)}, \\
& r_{2}=\frac{A\left(1-e_{2}^{2}\right)}{1+e_{2} \cos \left(\theta_{2}\right)},
\end{aligned}
$$

where $r_{1}$ and $r_{2}$ represent the radius of pitch curve of driving gear and driven gear, respectively. $A$ is the long half shaft of elliptic gear. $e_{1}$ and $e_{2}$ are the eccentricity of the driving and driven gears, respectively. $c$ is the distance from the centre of elliptic symmetry to the focus, and $c=e A . \theta_{1}$ and $\theta_{2}$ are the rotation angles of driving and driven gears, respectively. The following are the relations between the rotation angles of driving and driven gears of elliptic gear pair:

$$
\theta_{2}=2 a c \tan \left[\left(\frac{1+e_{1}}{1-e_{1}}\right) \tan \frac{\theta_{1}}{2}\right] \text {. }
$$




\subsection{Torque of Elliptic Gear Pair}

The power transmission of the elliptic gear pair is similar to that of a cylindrical gear, and its transmission model is shown in Fig. 2a. Due to the time-varying curvature radius of the pitch curve of elliptic gears, there are certain differences among the teeth. Even if the load torque $T_{L}$ on the driven shaft is constant, the torque fluctuation may occur on the driving side [20]. Therefore, in order to analyse the transmission torque of the elliptic gear pair, the load torque borne by the driven gear can be transformed into the driving gear, as shown in Fig. $2 b$.

The constant torque applied to the driven gear will lead to torque imbalance on the driving gear. Due to the time-varying transmission ratio function of the elliptic gear pair, the driven gear will produce a certain moment of inertia in the case of variable angular velocity. Therefore, under the condition that the drive shaft rotates at a constant speed, the total torque required to drive the load torque can be expressed as:

$$
T_{1}=\frac{T_{2}}{i_{12}}=\frac{T_{L}+I_{2} \alpha_{2}}{i_{12}},
$$

where $T_{1}$ and $T_{2}$ are the loads on the driving and driven gears, respectively, $T_{L}$ is the load torque, $I_{2}$ is the moment of inertia of the driven gear, and $\alpha_{2}$ is the angular acceleration of the driven gear.

It can be seen from Fig. 2 that when the angle of the elliptic gear is $\theta_{1}=\omega_{1} t$. The design parameters of the two elliptical gears are the same, so $e_{1}=e_{2}$. The transmission ratio of the elliptic gear pair can be expressed as:

$$
i_{12}=\frac{a}{r_{1}}-1=\frac{1+e_{1}^{2}-2 e_{1} \cos \left(\omega_{1} t\right)}{1-e_{1}^{2}} .
$$

Then, the angular velocity and angular acceleration of the driven gear can be expressed as:

$$
\begin{gathered}
\omega_{2}=\frac{\left(1-e_{1}^{2}\right) \omega_{1}}{1+e_{1}^{2}-2 e_{1} \cos \left(\omega_{1} t\right)}, \\
\alpha_{2}=\frac{d \omega_{2}}{d t}=-\frac{2 \omega_{1}^{2} e_{1}\left(1-e_{1}^{2}\right) \sin \left(\omega_{1} t\right)}{\left[1+e_{1}^{2}-2 e_{1} \cos \left(\omega_{1} t\right)\right]^{2}} .
\end{gathered}
$$

Because the profile of elliptic gear remains involute, its moment of inertia can be calculated according to the method of cylindrical gear. The elliptic gear is approximately equivalent to a cam, and the moment of inertia per unit tooth width of the elliptic gear can be expressed as:

$$
I=\frac{\rho_{0}\left[a\left(1-e_{1}^{2}\right)\right]^{4}}{2} \int_{0}^{\AA} \frac{\mathrm{d} \theta_{1}}{\left(1+e_{1} \cos \theta_{1}\right)^{4}} .
$$

Let $u=1+e \cos \theta_{1}$, then Eq. (9) can be simplified as follows:

$$
I=\left.\frac{\rho_{0}\left[a\left(1-e_{1}^{2}\right)\right]^{4}}{2\left(e^{2}-1\right)^{3}} M\right|_{0} ^{\pi}=\frac{\pi \rho_{0}\left[a\left(1-e_{1}^{2}\right)\right]^{4}\left(2+3 e_{1}^{2}\right)}{4\left(1-e_{1}^{2}\right)^{3} \sqrt{1-e_{1}^{2}}},
$$

where $\rho_{0}$ is the density of elliptic gear and $M$ is as follows:

$$
\begin{aligned}
M= & {\left[\frac{\left(e_{1}^{2}-1\right)^{2}}{3}-\frac{5\left(1+e_{1} \cos \theta_{1}\right)\left(e_{1}^{2}-1\right)}{6}+\frac{2\left(1+e_{1} \cos \theta_{1}\right)^{2}\left(e_{1}^{2}-1\right)}{3}+\frac{5\left(1+e_{1} \cos \theta_{1}\right)^{2}}{2}\right] \cdot \frac{e_{1} \cos \theta_{1}}{\left(1+e_{1} \cos \theta_{1}\right)^{3}} } \\
& +\frac{2+3 e_{1}^{2}}{2 \sqrt{1-e_{1}^{2}}} \arcsin \left(\frac{e_{1}+\cos \theta_{1}}{1+e_{1} \cos \theta_{1}}\right) .
\end{aligned}
$$
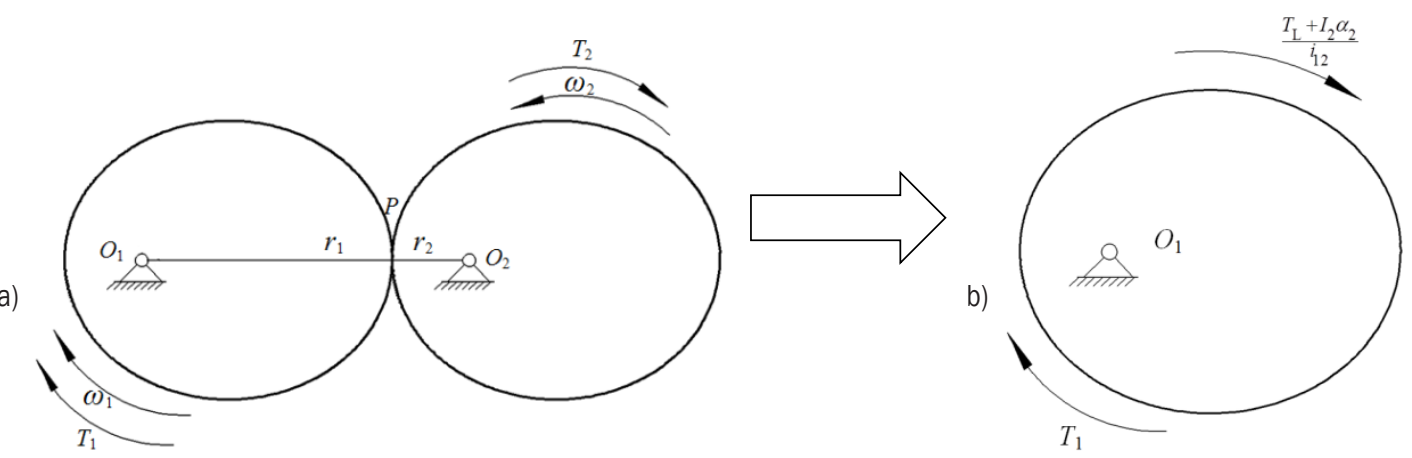

Fig. 2. Torque transmission model of elliptic gear pair;

a) the original elliptic gear meshing moment model, and b) the equivalent model after the load torque is applied to the driving gear 
Substituting Eqs. (6) to (9) into Eq. (5), we obtain:

$$
T_{1}=\frac{\left(1-e_{1}^{2}\right)\left[T_{L}\left(1+e_{1}^{2}-2 e_{1} \cos \left(\omega_{1} t\right)\right)^{2}-I_{2} 2 e_{1} \omega_{1}\left(1-e_{1}^{2}\right) \sin \left(\omega_{1} t\right)\right]}{\left(1+e_{1}^{2}-2 e_{1} \cos \left(\omega_{1} t\right)\right)^{3}} .
$$

\section{CONSTRUCTION OF ELLIPTIC GEAR TRANSMISSION TEST}

The elliptic gear test adopts a horizontal mechanism composed of a precision mechanical system, measurement and control system, measurement software and other parts. The names and distribution positions of the main components of the test bench are shown in Fig. 3. The schematic diagram of its working principle is shown in Fig. 4. The elliptical gear reducer is installed in the gear test platform, the input and output ends of the reducer are connected through a coupling, and the signal is transmitted to the controller through computer control. The controller transmits the implementation command to the sensor and the driver, provides power and load by driving the motor, and then transmits the power and load to the reducer, so that the reducer can operate normally. The torque sensor and the vibration sensor sequentially collect the experimental data required to be measured and transmit them back to the computer through the controller to obtain the required experimental data. The elliptic gear transmission test is shown in Fig. 5.

The main machine of elliptic gear transmission test is mainly composed of a mechanical system, including input end components, output end components, reducer mounting bracket, and other parts. Each component is installed on the $2.6 \mathrm{~m}$ long cast iron platform base with a T-groove. The mounting bracket of the reducer is fixed in the middle

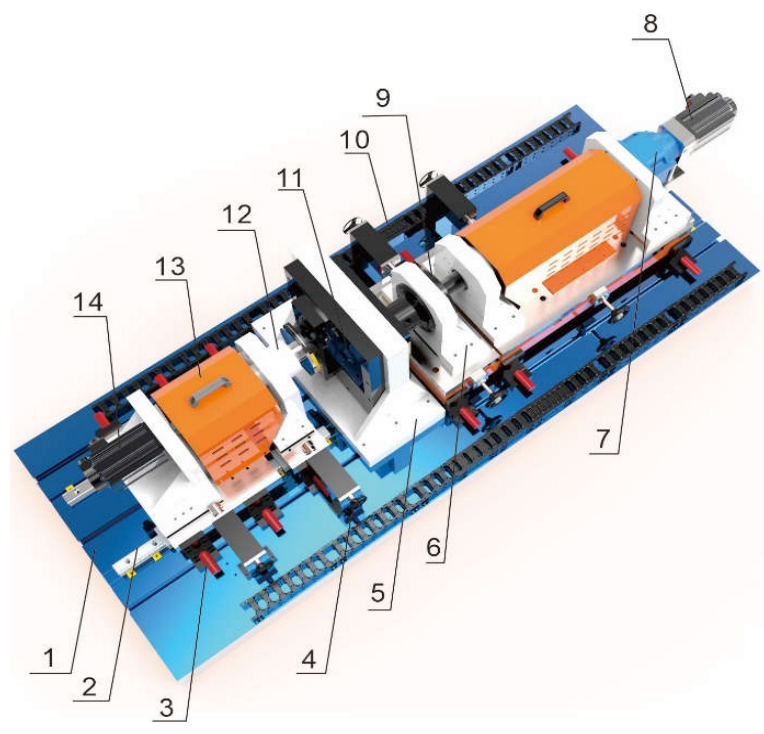

Fig. 3. The distribution of main engine components; 1 T-groove cast iron platform base; 2 linear guide rail; 3 Locking device; 4 hand wheel; 5 reducer base; 6 base; 7 Test planetary reducer; 8 Servo motor at output end; 9 Circular grating protective cover at output end; 10 drag chain; 11 reducer under test; 12 input end circular grating protective cover; 13 protective cover; 14 input servo motor

of the base. The left side is the input end assembly, and the right side is the output end assembly. The input end assembly includes input end motor slide

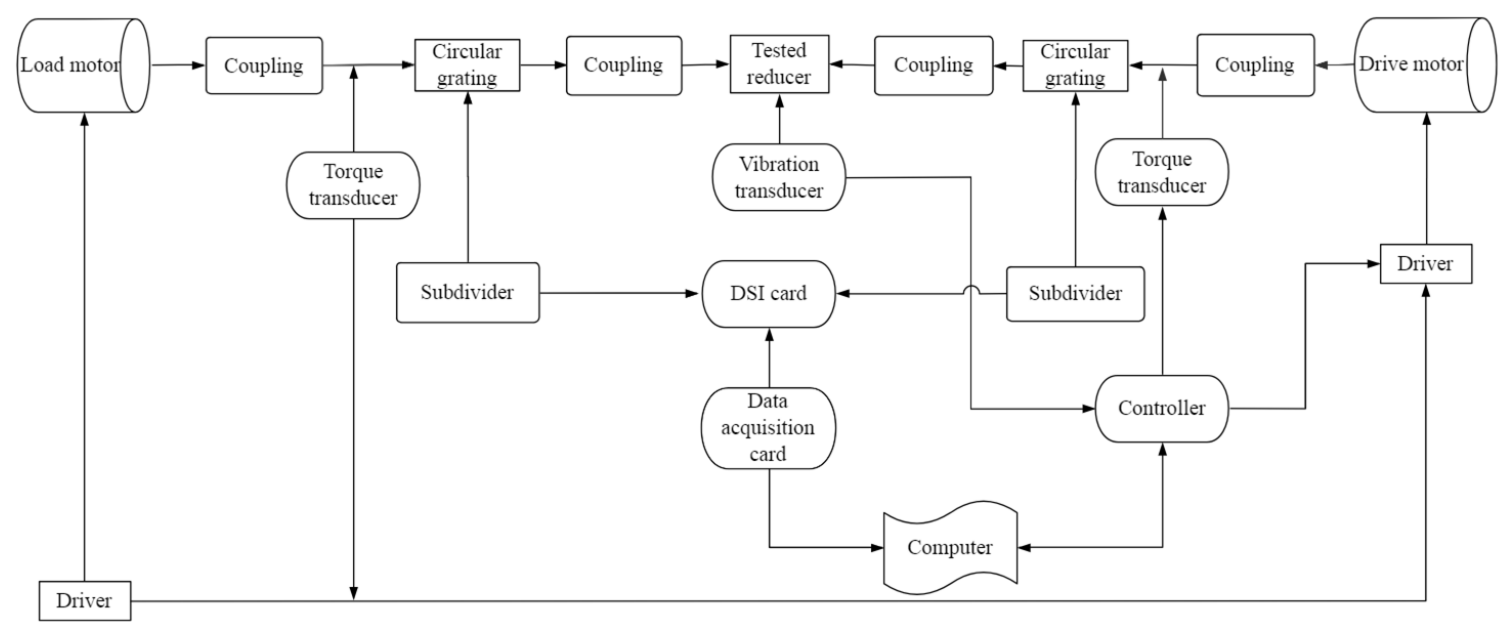

Fig. 4. Working principle of elliptic gear transmission test bench 
a)
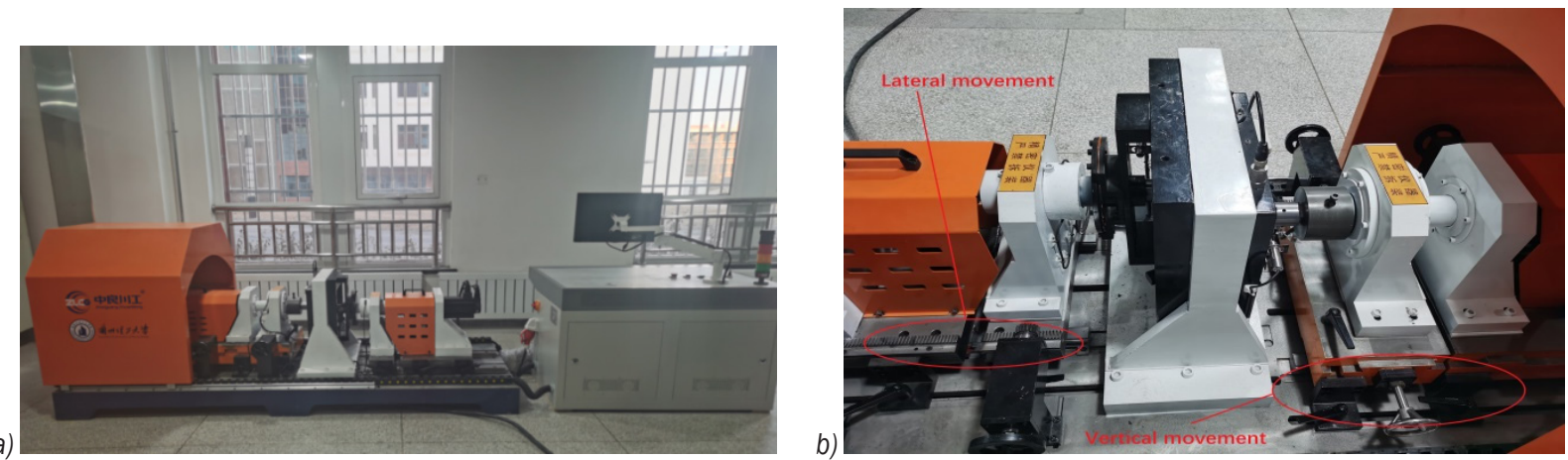

Fig. 5. The elliptic gear transmission test; a) overall view of the test bench, and b) partial view of the test bench

plate (installing input servo motor and input torque sensor) and input end grating encoder slide plate (installing input grating encoder). The output end assembly includes output end grating encoder slide plate (installing output grating encoder) and output end loading support slide plate (installing output servo motor and output torque sensor). Each slide plate is installed on the linear guide rail, which can be moved left and right through the hand gear to adjust the position. The input end is driven by an alternating current (AC) servo motor, which can work in speed mode and torque mode.

To realize the installation and test of different specifications and models of precision reducer, the test bench has a precision mounting bracket and supporting multi specification precision mounting accessories (connecting disc, input shaft and output shaft) so as to improve the universality of the test equipment. The whole system is controlled via an industrial computer, equipped with high-precision grating sensor system, high-precision torque sensor system and special measurement software, so as to realize the automatic measurement of the performance of precision reducer. The special feature of the testbed is that it can be used for various types of reducers.
The mounting bracket of the reducer is fixed in the middle of the base, and the linear guide rail is installed on the cast iron platform base. The movement of the input and output components is realized through the gear rack mechanism.

The left-hand gear in Fig. $5 \mathrm{~b}$ can ensure the implementation of lateral movement. There are similar mechanisms in the input end assembly and output end assembly, which can ensure the sliding of the input end motor and grating encoder slide plate and realize the connection or disconnection between the encoder and the output shaft of the tested reducer and the connection or disconnection between the output torque sensor and the output shaft of the tested reducer. In Fig. 5b, the right-hand gear can realize the vertical movement of the output component, which can make the slide plate of the input end grating encoder slide. To realize the connection or disconnection between the input shaft of the measured reducer and the reducer, the slide plate of the input end motor, and the connection or disconnection between the grating encoder and the input end torque sensor. Fig. 6 shows the processed elliptic gear pair, and its design parameters are shown in Table 1.
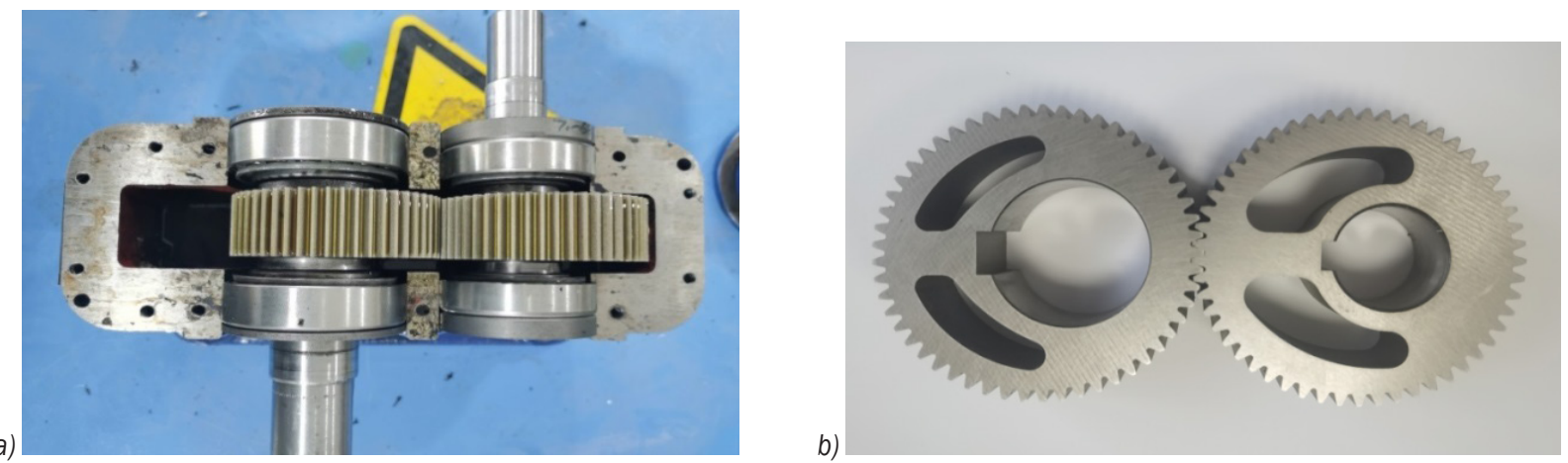

Fig. 6. The gear used in elliptic gear transmission experiment; a) elliptic gear reducer, and b) elliptic gear pair processed 
Table 1. Elliptic gear design parameters

\begin{tabular}{lc}
\hline Parameter & Value \\
\hline Module $m[\mathrm{~mm}]$ & 1.5 \\
\hline Number of teeth $z$ & 53 \\
\hline Centre distance $a[\mathrm{~mm}]$ & 80 \\
\hline Tooth width $B$ [mm] & 28 \\
\hline Eccentricity $e$ & 0.2 \\
\hline Pressure angle $\left[^{\circ}\right]$ & 20 \\
\hline & $r=\frac{38.4}{1+0.2 \cos \theta}$ \\
\hline Equation of pitch curves & Structural steel \\
\hline Material & Oil lubrication \\
\hline Lubrication mode &
\end{tabular}

\section{TORQUE FLUCTUATION OF ELLIPTIC GEAR}

According to Eq. (10), the change trend of the torque of the driving and driven gears of the elliptic gear pair under different eccentricity and load torque conditions can be obtained, as shown in Figs. 7 and 8.
In Fig. 7, with the increase of eccentricity, the torque of the driving and driven gears of the elliptic gear increases. The change trend of driving gear is more obvious. When the eccentricity is 0 , the torque of the driving and driven gears of the elliptic gear pair is constant and will not fluctuate. When the eccentricity is not 0 , the torque fluctuation of the driving and driven gears will occur. With the increase of eccentricity, the change of torque of driven gear is more regular.

In contrast, the change of driving gear shows the same trend, but there are some differences between different eccentricities. This is because the driven gear is connected to the output and the torque at the output is constant. The driven gears move along a specific transmission ratio function under the driving gear. The inconsistency of the tooth profile of the elliptic gear pair makes the torque difference between the driving gears and the driven gears.

Fig. 8, with the increase of load torque, also presents the same change trend. In contrast, the load
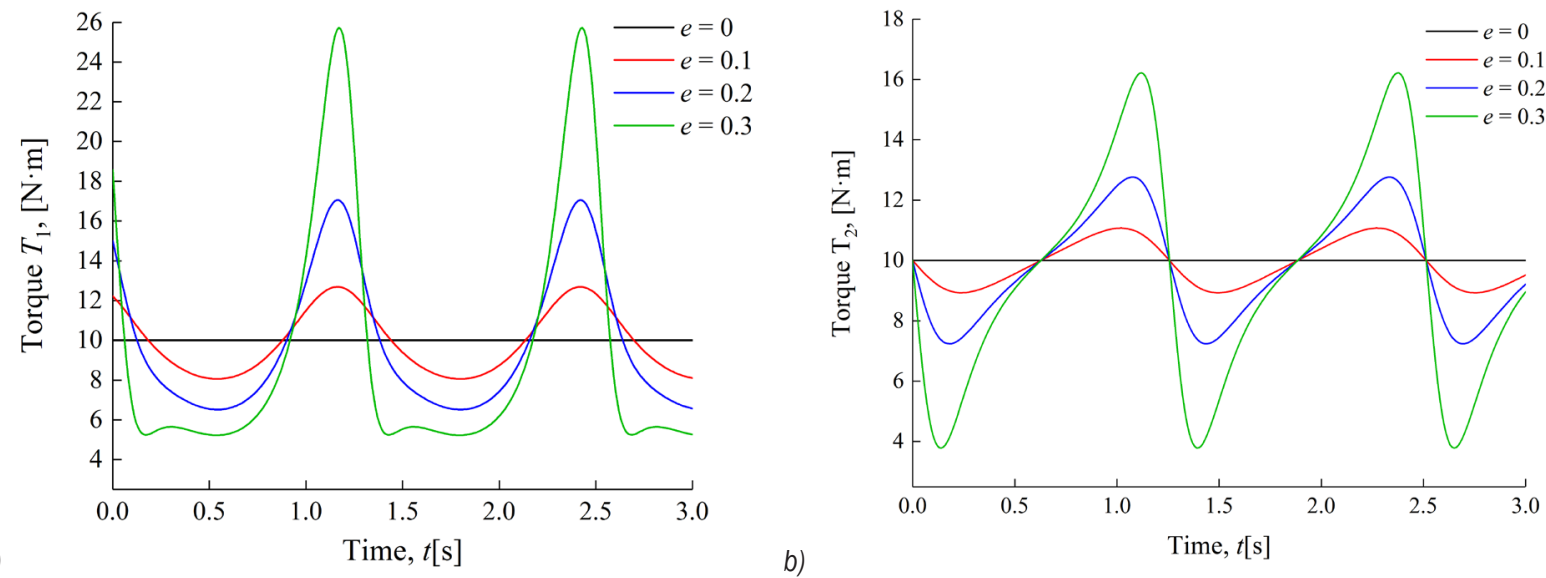

Fig. 7. Effect of eccentricity on torque of a) driving and b) driven gears
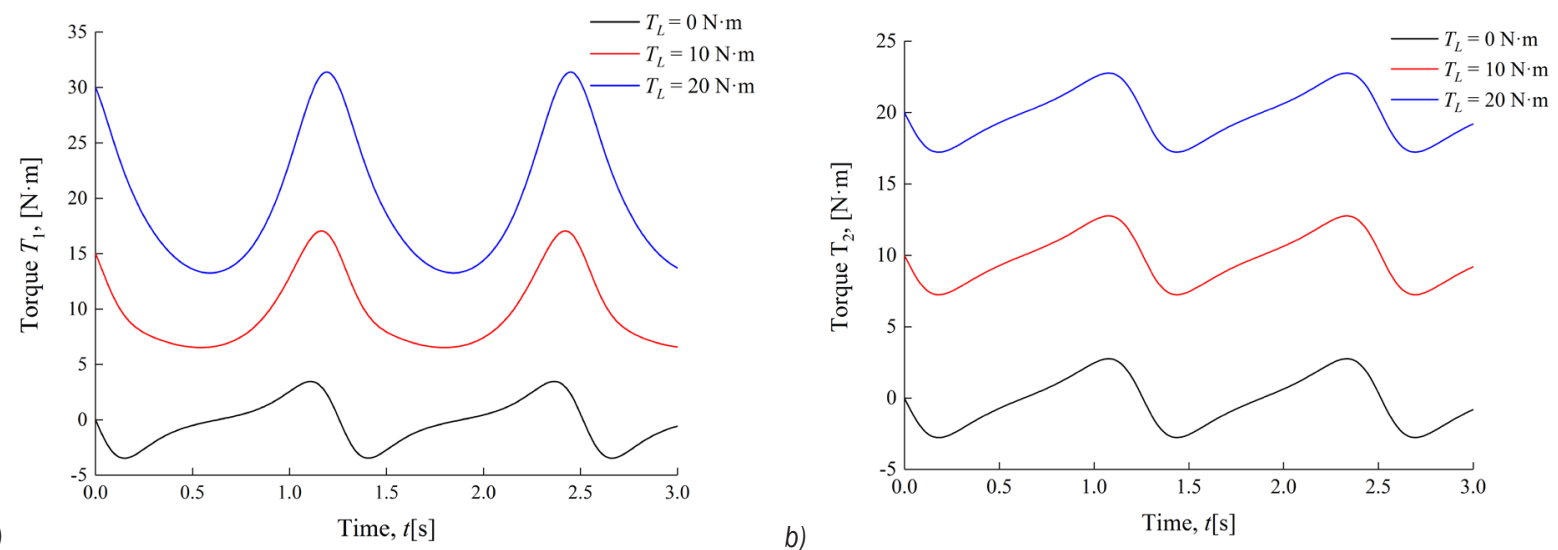

Fig. 8. Influence of load torque on a) driving and b) driven gear torque 
change of driven gear is more uniform and smoother. The moment of inertia is produced by the non-uniform rotation of the elliptic gear. If the inertia moment is greater than the load moment, the torque of the driving shaft is opposite to the working driving direction, which will cause impact on the non-meshing tooth side of the gear. In Fig. 8, when the load torque is 0 , that is, under no-load condition, the minimum torque of the driving and driven gears of the elliptic gear pair will be less than 0 , which is negative and shows a periodic trend. This shows that there is tooth surface separation, which will lead to the vibration and noise of the gear transmission system, which is not conducive to the normal work of the system. With the increase of load torque, the phenomenon that the minimum torque of driving gear and driven gear is less than 0 will disappear, which indicates that the existence of load will always lead to the phenomenon of tooth separation.

\section{TRANSMISSION EFFICIENCY OF ELLIPTIC GEAR TRANSMISSION SYSTEM}

In view of the inconsistency of elliptic gear tooth profile and the complexity of applicable working conditions, especially for reciprocating motion and forward-and-reverse motion (reversing device of pumping unit), it is necessary to analyse its transmission efficiency under the condition of forward and reverse motion so as to provide guidance for practical application. In the process of the experiment, the rated output torque is preset. When the reducer is loaded from 0 to rated torque by driving motor, the torque data of input and output are collected. Each group collects 99 data points. The transmission efficiency of the elliptic gear pair is analysed by setting different operating parameters (torque and speed).

\subsection{Torque Analysis of Elliptic Gear Pair}

Figs. 9 to 11 show the change trend of input shaft torque and output shaft torque under the condition of constant speed and increasing gradient of rated load torque.

With the increase of rated load torque, the torque of the input and output ends is increasing. In contrast, the input and output torque in the reverse case are larger than that in the case of positive rotation. The torque fluctuation of the output is small, and the input torque presents periodic change. With the increase of rated input torque, the difference between the two kinds of steering gradually increases. This is consistent with the torque fluctuation analysis results. The output torque is less than the input torque: the torque $T_{1}$ of the driving gear is greater than the torque $T_{2}$ of the driven gear. Therefore, the correctness of the torque calculation method of the ellipse gear proposed in this paper is proved.

Figs. 12 and 13 show the change trend of input shaft torque and output shaft torque under clockwise and counterclockwise conditions when the load torque remains constant and the speed changes. According to the analysis in Fig. 9, with the increase of speed, the torque at the input and output end also presents a periodic trend. With the increase of the speed, the fluctuation of the torque at the input end and the torque at the output end is also intensified. Similar to the distribution trend in Figs. 8 to 10 , the input and output torques under clockwise rotation are
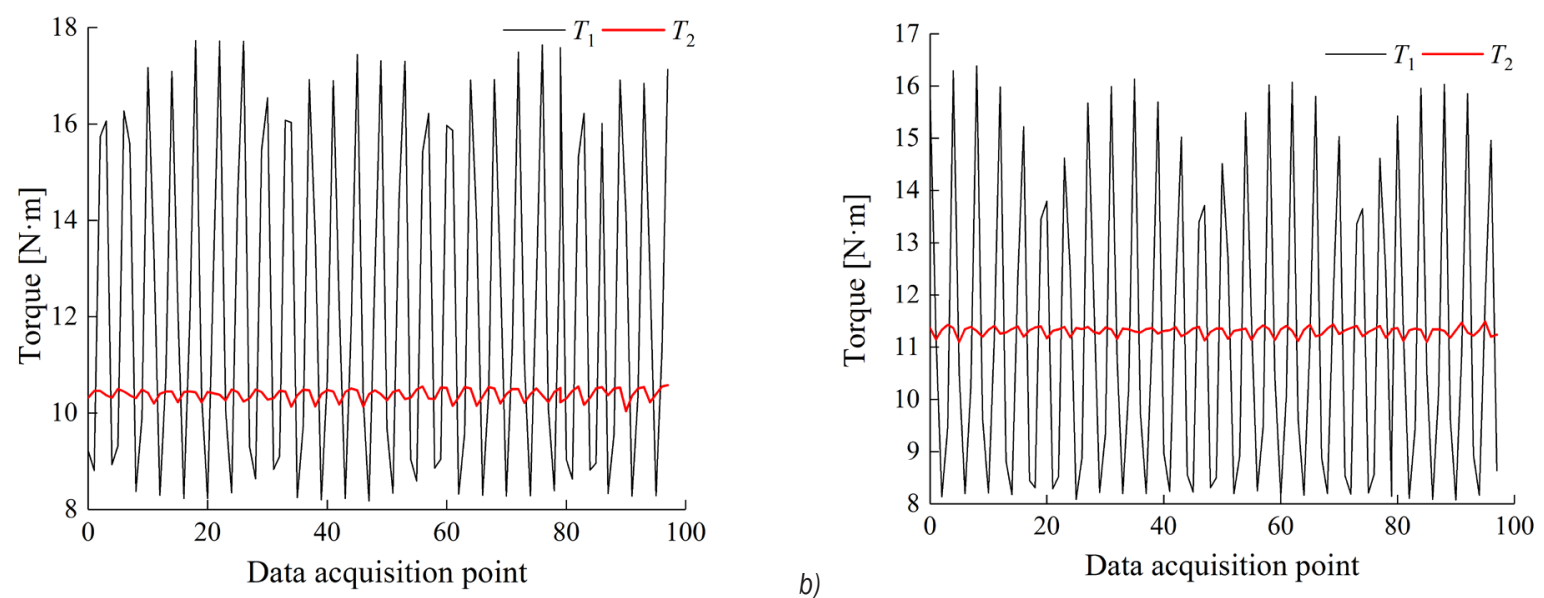

Fig. 9. The torque distribution law of elliptic gear pair when $T_{L}=5 \mathrm{~N} \cdot \mathrm{m}$; a) $n=5 \mathrm{r} / \mathrm{min}$, and b) $n=-5 \mathrm{r} / \mathrm{min}$ 


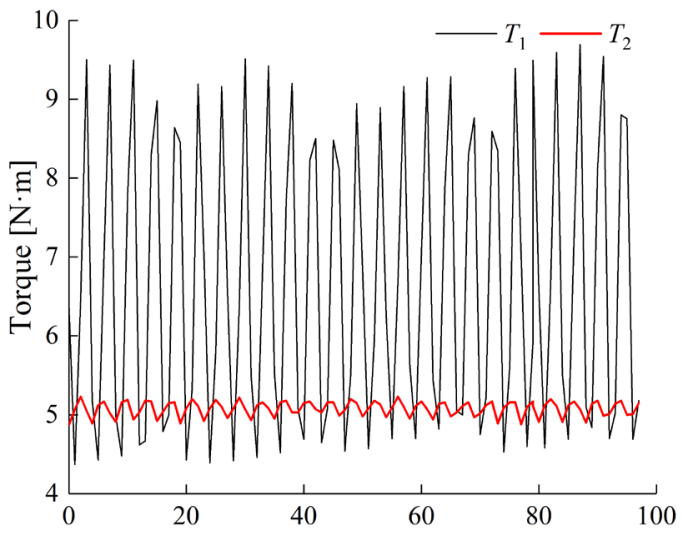

a)

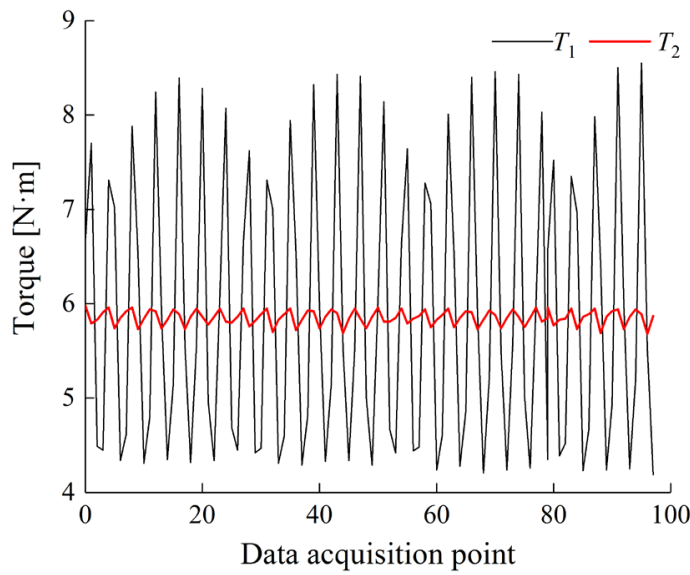

b)

Fig. 10. The torque distribution law of elliptic gear pair when $T_{L}=10 \mathrm{~N} \cdot \mathrm{m}$; a) $n=5 \mathrm{r} / \mathrm{min}$, and b) $n=-5 \mathrm{r} / \mathrm{min}$
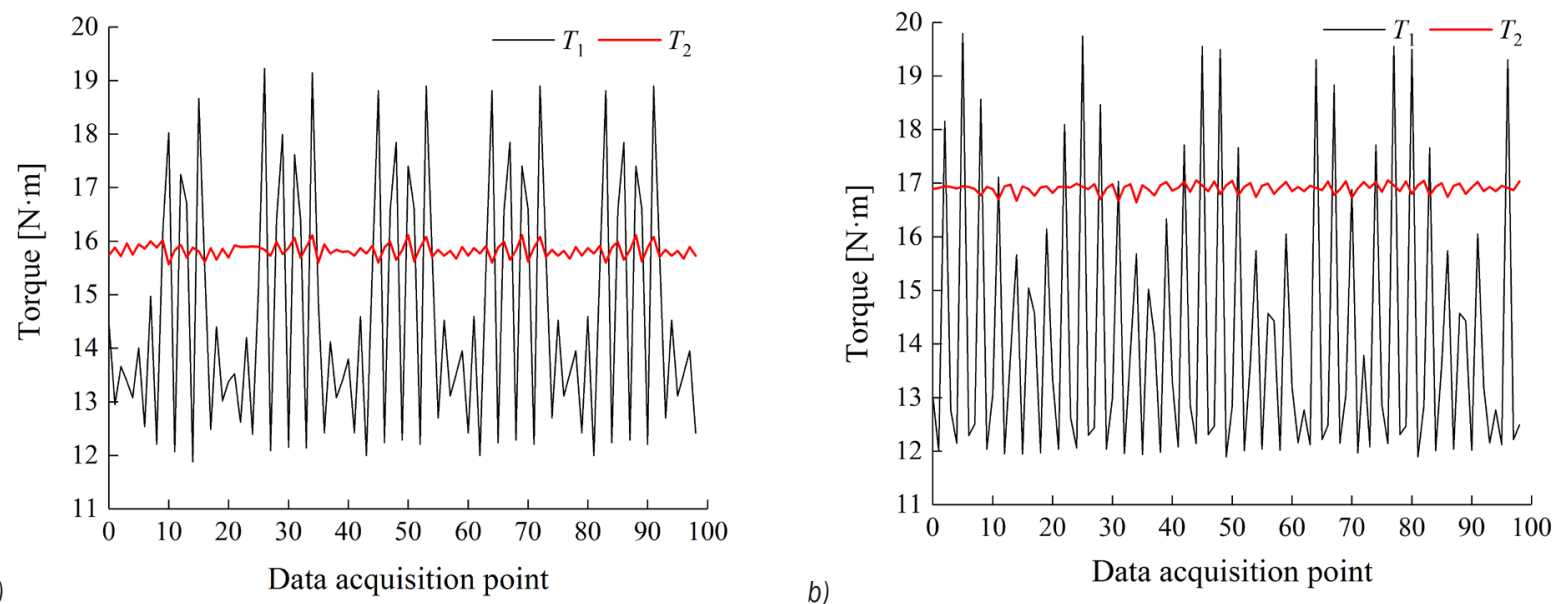

Fig. 11. The torque distribution law of elliptic gear pair when $T_{L}=15 \mathrm{~N} \cdot \mathrm{m}$; a) $n=5 \mathrm{r} / \mathrm{min}$, and b) $n=-5 \mathrm{r} / \mathrm{min}$
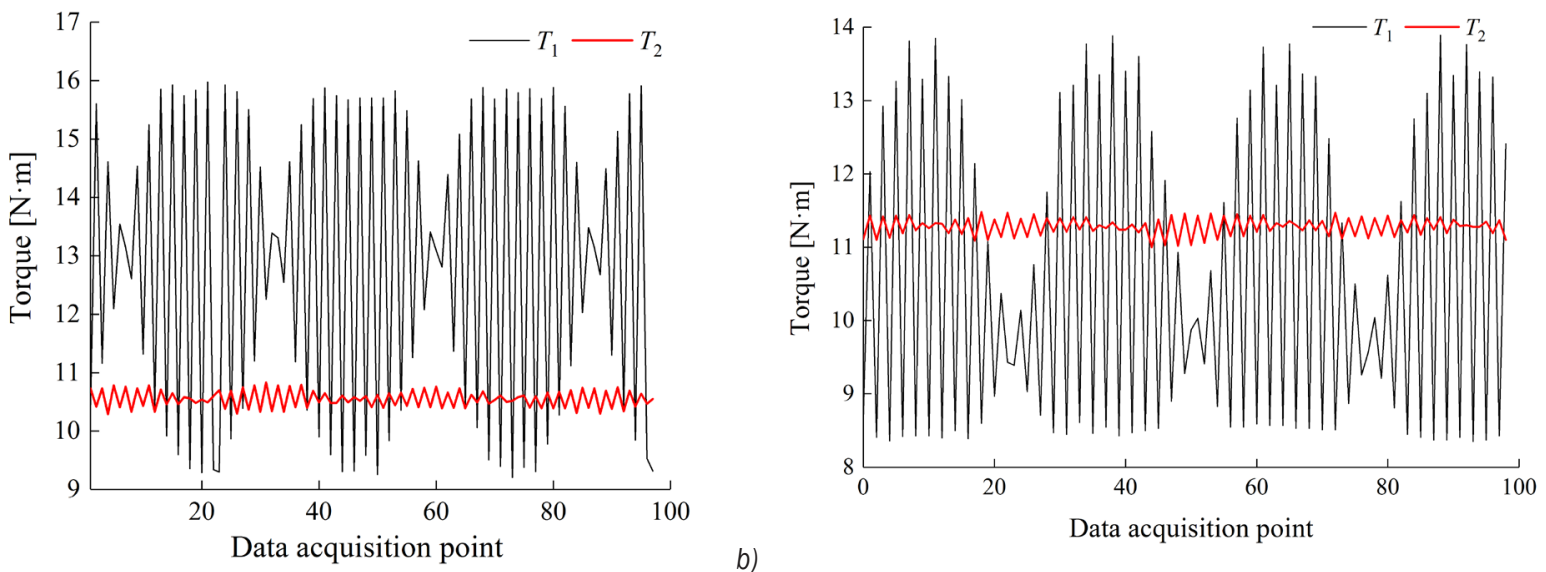

Fig. 12. The torque distribution law of elliptic gear pair when $T_{L}=10 \mathrm{~N} \cdot \mathrm{m}$; a) $n=10 \mathrm{r} / \mathrm{min}$, and b) $n=-10 \mathrm{r} / \mathrm{min}$

greater than those under counterclockwise rotation, which is related to the order of clockwise and counterclockwise rotation during the experiment. The first is the clockwise rotation experiment, and the second is the counterclockwise rotation experiment. Due to the existence of friction torque, starting torque, and dynamic backlash between tooth profiles at the beginning of counterclockwise rotation after 

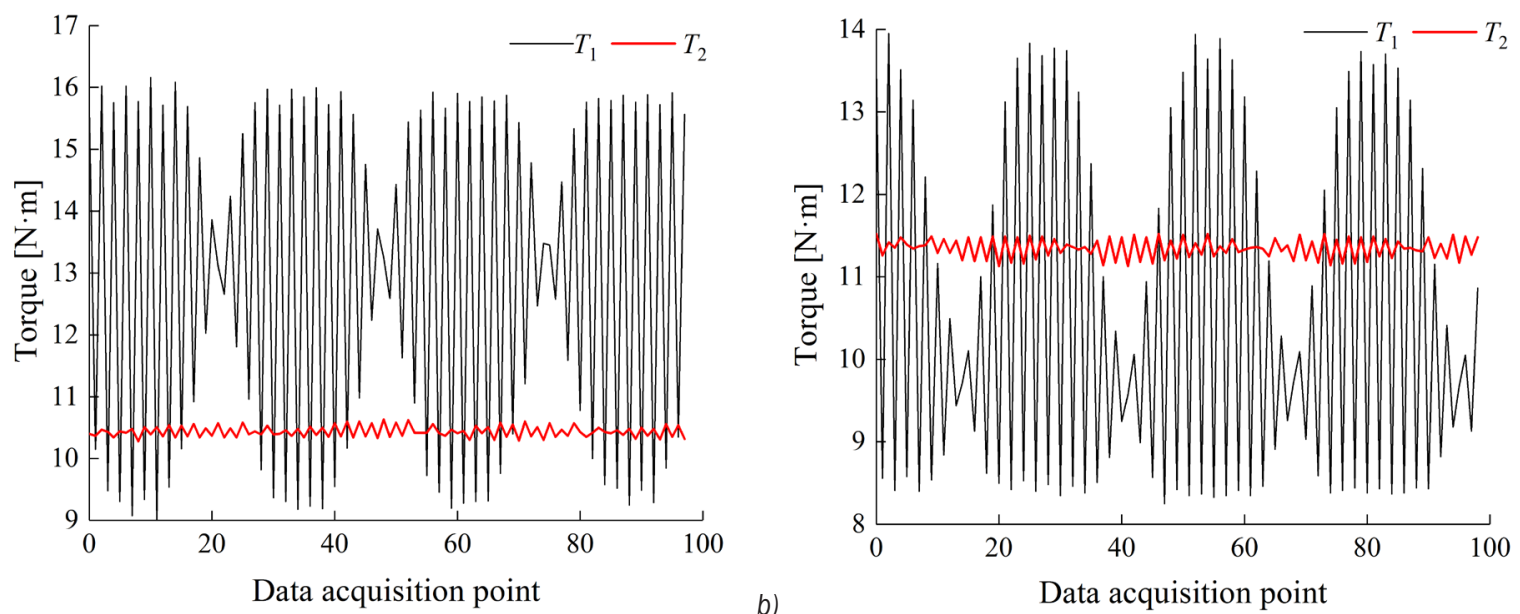

Fig. 13. The torque distribution law of elliptic gear pair when $T_{L}=10 \mathrm{~N} \cdot \mathrm{m}$; a) $n=20 \mathrm{r} / \mathrm{min}$, and b) $n=-20 \mathrm{r} / \mathrm{min}$

clockwise rotation, the torque under counterclockwise rotation is greater than that under clockwise rotation. Consistent with the previous analysis results, the torque $T_{1}$ of the driving gear is greater than that of the driven gear $T_{2}$, which further verifies the correctness of the torque calculation method of the elliptic gear proposed in this paper. It also shows that the change trend of the output torque and input torque of the elliptic gear transmission system will not change significantly with the increase of the speed, but there is a slight difference in the value.

There is a certain error in the data collection process, which will cause a certain difference between the torque $T_{1}$ at the input end and the torque $T_{2}$ at the output end, which will affect the instantaneous transmission efficiency calculation of the gear transmission system. The way we reduce the error is to collect data multiple times, and the trend of the collected data is basically consistent with the theoretical analysis, which also verifies the correctness of our experiment.

\subsection{Analysis of Transmission Efficiency of Elliptic Gear Pair}

Figs. 14 to 16 show the distribution law of instantaneous transmission efficiency calculated by Eq. (1) while keeping the speed constant and the rated load torque $T_{2}$ gradient changing. Under the two steering conditions, the instantaneous transmission efficiency of the elliptic gear pair changes all the time. In contrast, the transmission efficiency of the counterclockwise transient is greater than that of the clockwise transient. With the increase of rated load torque, the instantaneous transmission efficiency of the elliptic gear pair gradually presents a periodic trend, and the periodicity is more obvious.

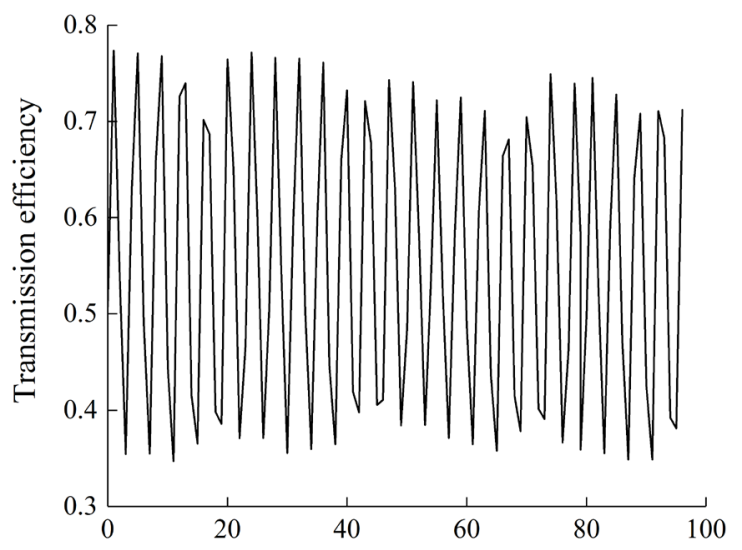

a)

Data acquisition point

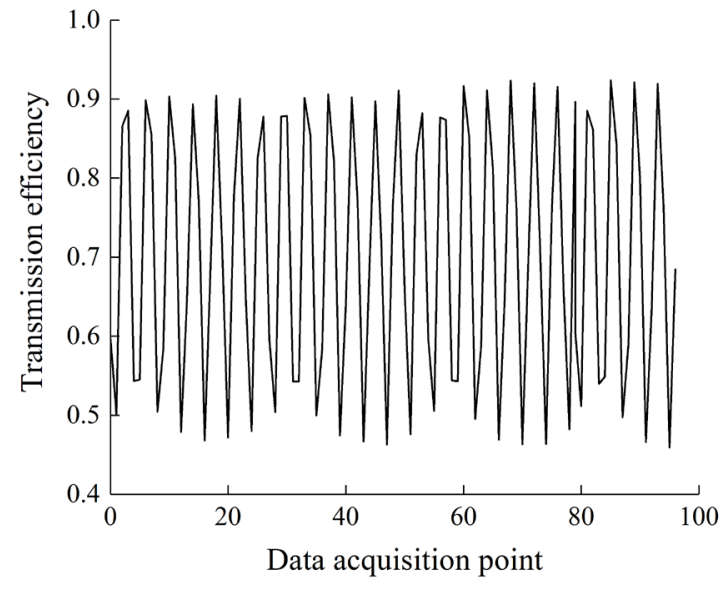

Fig. 14. The transmission efficiency of elliptic gear when $T_{L}=5 \mathrm{~N} \cdot \mathrm{m}$; a) $n=5 \mathrm{r} / \mathrm{min}$, and b) $n=-5 \mathrm{r} / \mathrm{min}$ 

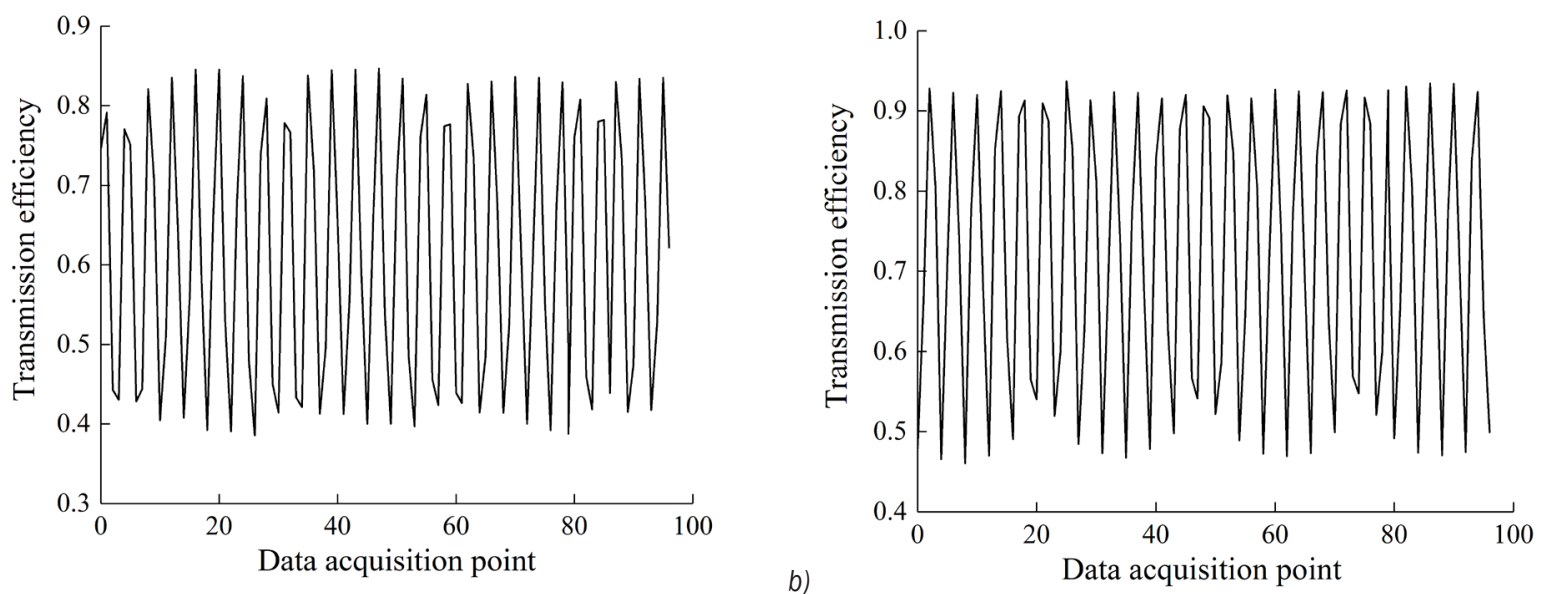

Fig. 15. The transmission efficiency of elliptic gear when $T_{L}=10 \mathrm{~N} \cdot \mathrm{m}$; a) $n=5 \mathrm{r} / \mathrm{min}$, and $\mathrm{b}$ ) $n=-5 \mathrm{r} / \mathrm{min}$

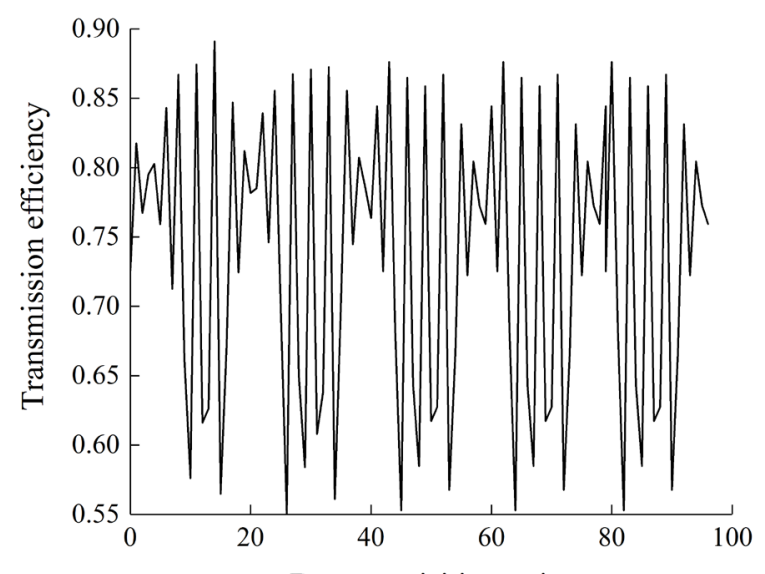

a)

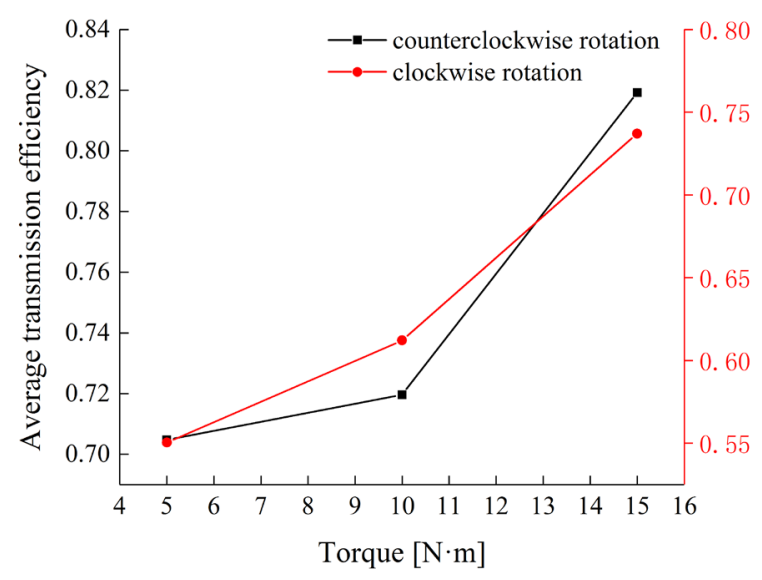

Fig. 17. The variation trend of transmission efficiency of elliptic gear with torque

Fig. 17 shows the change trend of average transmission efficiency of elliptic gear pair with the

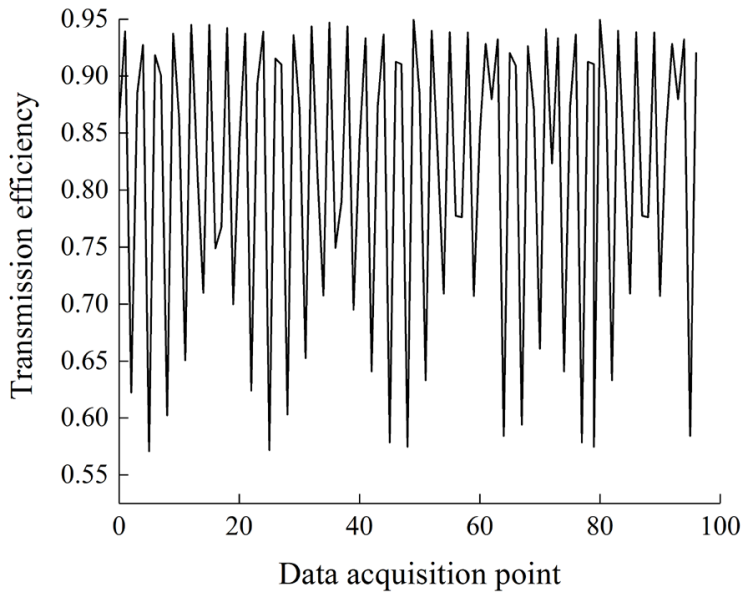

$T_{L}=15 \mathrm{~N} \cdot \mathrm{m}$; a) $n=5 \mathrm{r} / \mathrm{min}$, and b) $n=-5 \mathrm{r} / \mathrm{min}$

change of load torque. With the increase of the load torque, the transmission efficiency of the elliptic gear pair shows an increasing trend. Therefore, on the premise of meeting the actual working conditions and the established motion law, increasing the load torque is conducive to improving the transmission efficiency of the elliptic gear pair.

Figs. 18 to 20 show the distribution law of instantaneous transmission efficiency of elliptic gear pair under clockwise and counterclockwise conditions when the load torque remains constant, and the speed gradient changes. It is consistent with the previous analysis when the speed is constant, the load gradient changes, and the transmission efficiency in counterclockwise transient is greater than that in clockwise transient. However, under the two steering conditions, there is a periodic trend, and with the increase of speed, the periodicity is gradually obvious. 

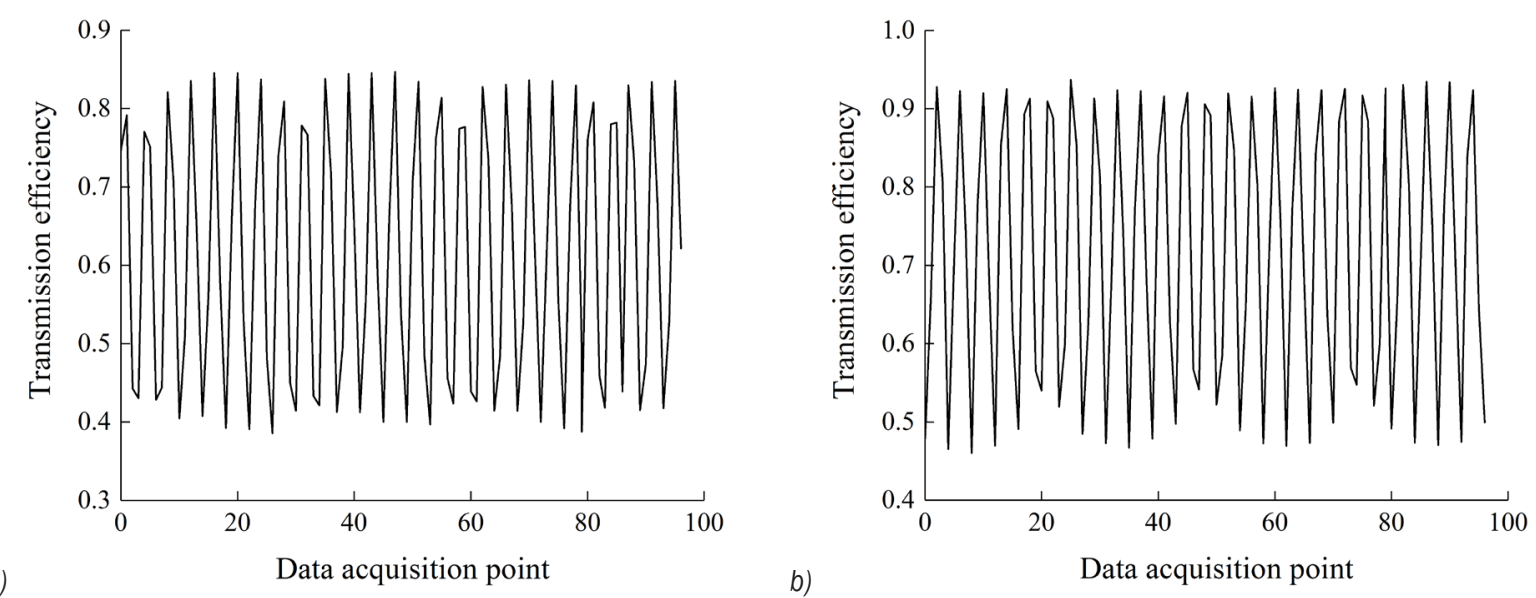

Fig. 18. Transmission efficiency of elliptic gear when $T_{L}=10 \mathrm{~N} \cdot \mathrm{m}$; a) $n=5 \mathrm{r} / \mathrm{min}$, and b) $n=-5 \mathrm{r} / \mathrm{min}$

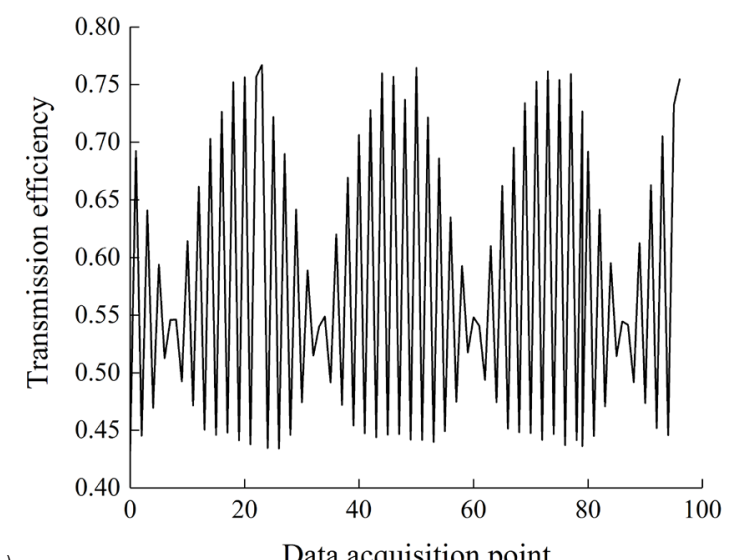

a)

Data acquisition point

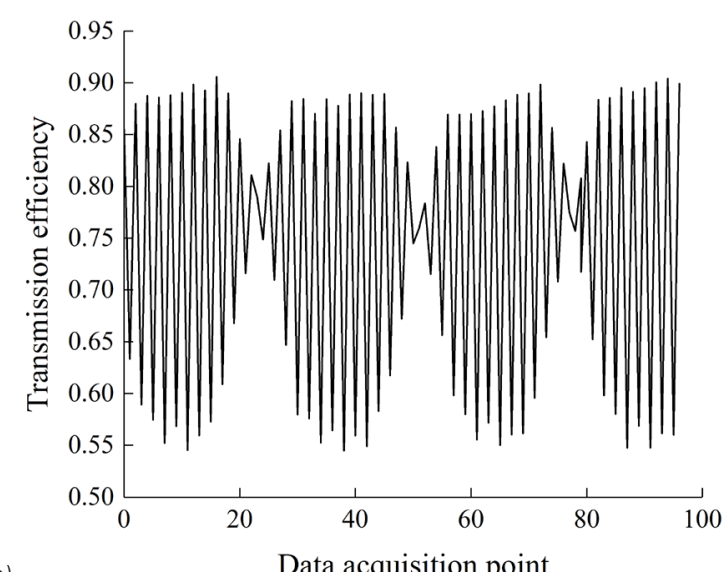

Fig. 19. Transmission efficiency of elliptic gear when $T_{L}=10 \mathrm{~N} \cdot \mathrm{m}$; a) $n=10 \mathrm{r} / \mathrm{min}$, and b) $n=-10 \mathrm{r} / \mathrm{min}$

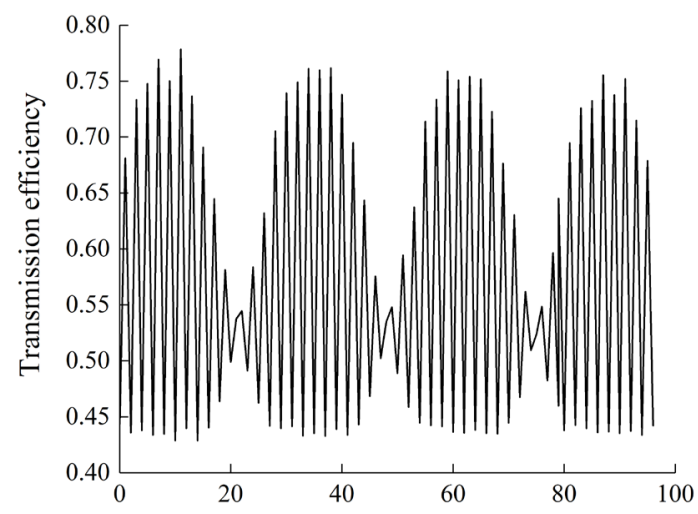

a) Data acquisition point

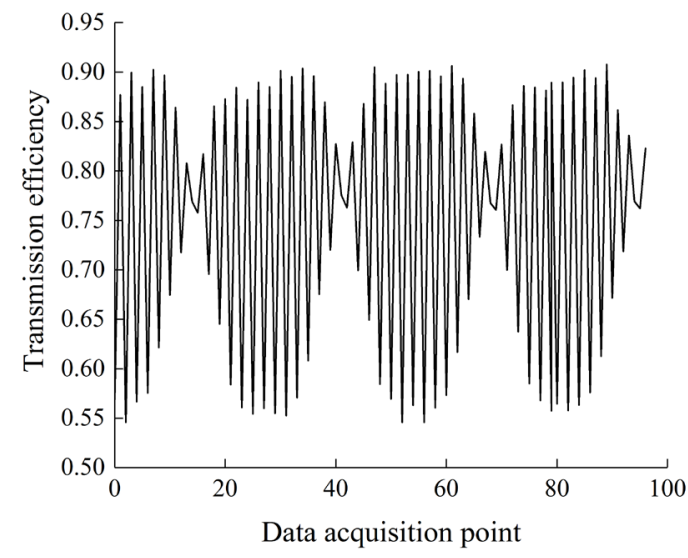

Fig. 20. Transmission efficiency of elliptic gear when $T_{L}=10 \mathrm{~N} \cdot \mathrm{m}$; a) $n=20 \mathrm{r} / \mathrm{min}$, and b) $n=-20 \mathrm{r} / \mathrm{min}$

In contrast, the counterclockwise transmission efficiency is greater than the forward transmission efficiency, and the transmission efficiency decreases with the increase of speed.
Fig. 21 shows the change trend of the average transmission efficiency of clockwise and counterclockwise rotation of elliptic gear pair with the change of speed. With the increase of rotation 
speed, the average transmission efficiency clockwise and counterclockwise rotation of the elliptic gear pair presents a decreasing trend. This is closely related to the non-linear change of instantaneous coincidence degree and transmission ratio of elliptic gear. Therefore, the elliptic gear pair can present high instantaneous transmission efficiency at low speed. In the process of engineering application, the instantaneous transmission efficiency can be improved by appropriately reducing the speed on the premise of meeting the established working conditions and motion rules.

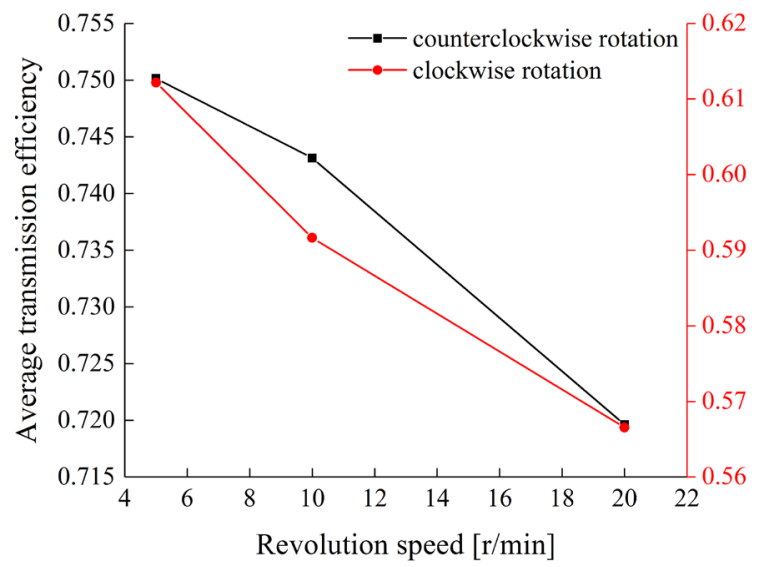

Fig. 21. The variation trend of elliptic gear transmission efficiency with torque

Due to the inconsistency of the tooth profile of the elliptic gear, the instantaneous transmission efficiency during the meshing process changes all the time, and its transmission efficiency will be lower than that of a general cylindrical gear. However, the elliptic pair is mainly suitable for low-speed, high-torque occasions and for some special variable-speed sports occasions. Therefore, under the conditions of low speed and high torque, its instantaneous transmission efficiency can reach more than $80 \%$, which can meet the requirements of working conditions.

\section{CONCLUSIONS}

Based on the load fluctuation model of elliptic gear, the test-bed of elliptic gear transmission is built, and the torque data values of input and output in forward and reverse rotation are obtained. On this basis, the transmission efficiency of the elliptic gear pair is calculated and obtained, and the influence of load torque and speed on the transmission efficiency of the system is analysed. The results show that:
1. Due to the time-varying pitch curve radius of the elliptic gear pair, the tooth profile is inconsistent, which makes the torque at the input end and output end have certain differences under the conditions of forward rotation and reverse rotation, so the transmission efficiency will have certain differences. Under the action of load torque, the torque on the driving and driven gears of elliptic gear will increase with the increase of the eccentricity and load torque of elliptic gear.

2. The load torque and speed have a certain influence on the transmission efficiency of the elliptic gear transmission system. The transmission efficiency will decrease with the increase of speed and increase with the increase of load torque, which also shows that the non-circular gear transmission system represented by elliptic gear is suitable for low speed and high torque conditions.

3. In view of the commonness of elliptic gear and non-circular gear and the subordinate relationship between them, the calculation method, and experimental means of transmission efficiency of elliptic gear proposed in this paper can be used for other types of non-circular gear transmission systems, and can provide some theoretical guidance for the calculation of transmission efficiency.

\section{ACKNOWLEDGEMENTS}

The research was support by the National Natural Science Founding of China (No. 51765032), and the Open Fund of Hubei Key Laboratory of Mechanical Transmission and Manufacturing Engineering at Wuhan University of Science and Technology (Grant No. MTMEOF2020B03)

\section{REFERENCES}

[1] Liu, M., Liu, D., Zhang, K. (2020). Transmission theory and efficiency analysis of non-constant transmission of end face gear with movable teeth. Journal of Mechanical Design, vol. 34, no. 10, p. 20-25. (in Chinese)

[2] Liu, M., Liu, D., Zhang, K., Yan, Y, (2016). Transmission theory and meshing efficiency of movable tooth transmission with speed integration. Machine Design and Research, vol. 32, no. 05, p. 64-67. (in Chinese)

[3] Dong, C., Liu, Y., Wei, Y., Yun, B., Li, D., Dong, Z. (2020). Analysis on meshing characteristics and transmission error of elliptic gears. Mathematical Problems in Engineering, vol. 2020, art. ID 201728, DOI:10.1155/2020/2017218.

[4] Dong, C., Liu, Y., Wei, Y. (2019). Dynamic contact characteristics analysis of elliptic cylinder gear under different load conditions. Journal of Huazhong University of Science \& 
Technology (Natural Science Edition), vol. 48, no. 8, p. 103107.

[5] Dong, C., Liu, Y., Wei, Y. (2020). Dynamic meshing characteristics of elliptic cylinder gear based on tooth contact analysis. International Journal of Engineering Transaction A: Basics, vol. 33, no. 4, p. 676-685, D0l:10.5829/ IJE.2020.33.04A.19.

[6] Dong, C., Liu, Y., Wei, Y. (2020). Meshing error of elliptic cylinder gear based on tooth contact analysis. International Journal of Engineering Transaction A: Basics, vol. 33, no. 7, p. 1364-1374, D0I:10.5829/IJE.2020.33.07A.24.

[7] Tucker, R.W., Wang, C., Librovich, B. (2003). Mathematical modelling of rotary vane engines. Proceedings of the Institution of Mechanical Engineers, Part C: Journal of Mechanical Engineering Science, vol. 217, no. 6, p. 687-704, DOl:10.1243/095440603321919608.

[8] Diez-lbarbia, A., Fernandez-Del-Rincon, A., Garcia, P., DeJuan, A., Iglesias, M., Viader, F. (2018). Assessment of load dependent friction coefficients and their influence on spur gears efficiency. Meccanica, vol. 53, p. 425-445, DOl:10.1007/s11012-017-0736-8.

[9] Wang, C., Cui, H.Y., Zhang, Q.P., Wang, W.M. (2016) An approach of calculation on sliding friction power losses in involute helical gears with modification. Proceedings of the Institution of Mechanical Engineers, Part C: Journal of Mechanical Engineering Science, vol. 203-210, no. 9, p. 1521-1531, D0I:10.1177/0954406215573977.

[10] Wang, C., Shi, Z. (2017). A dynamic calculation method of sliding friction losses for a helical gear pair. Journal of the Brazilian Society of Mechanical Sciences and Engineering, vol. 39, p. 1521-1528, D0l:10.1007/s40430-016-0585-8.

[11] Wang, C. (2020). Dynamic model of a helical gear pair considering tooth surface friction. Journal of Vibration and Control, vol. 26, no. 15-16, p. 1356-1366, DOl:10.1177/1077546319896124.

[12] Wang, C., Ken, M. (2020). A calculation method of sliding friction coefficient on tooth surface for helical gear pair based on loaded tooth contact analysis and elastohydrodynamic lubrication theory. Proceedings of the Institution of Mechanical Engineers, Part J: Journal of Engineering Tribology, vol. 235, no. 8, p. 1551-1560, D0I:10.1177/1350650120966894.

[13] Wang, C., Wang, S., Wang, G. (2018). A method for calculating gear meshing efficiency by measured data from gear test machine. Measurement, vol. 119, p. 97-101, D0l:10.1016/j. measurement.2018.01.031.

[14] Wang, C. (2020). The effect of planetary gear/star gear on the transmission efficiency of closed differential double helical gear train. Proceedings of the Institution of Mechanical Engineers, Part C: Journal of Mechanical Engineering Science, vol. 234, no. 21, p. 4215-4223, DOI:10.1177/0954406220921205.

[15] Petry-Johnson, T.T., Kahraman, A., Anderson, N.E., Chase, D.R. (2008). An experimental investigation of spur gear efficiency. Journal of Mechanical Design, vol. 130, no. 6, art. ID 062601 , DOI:10.1115/1.2898876.

[16] Xu, H., Kahraman, A., Anderson, N.E., Maddock, D.G. (2007). Prediction of mechanical efficiency of parallel-axis gear pairs. Journal of Mechanical Design, vol. 129, no. 1, p. 58-68, DOI:10.1115/1.2359478.

[17] Li, S., Kahraman, A. (2010). Prediction of spur gear mechanical power losses using a transient elastohydrodynamic lubrication model. Tribology Transactions, vol. 53, no. 4, p. 554-563, DOI:10.1080/10402000903502279.

[18] Li, Y., Wang, G., Zou, S. (2017). The calculation of meshing efficiency of a new type of conical involute gear. Strojniški vestnik - Journal of Mechanical Engineering, vol. 63, no. 5, p. 320-330, DOl:10.5545/sv-jme.2016.3843.

[19] Liu, W., Peng, H., Cai, Z., Ma, X. (2021). Study on meshing efficiency of non-circular gear based on elastohydrodynamic lubrication. Journal of Mechanical Transmission, vol. 45, no. 2, p. 1-5, D0l:10.16578/j.issn.1004.2539.2021.02.001. (in Chinese)

[20] Gao, N., Meesap, C., Wang, S., Zhang, D: (2020). Parametric vibrations and instabilities of an elliptic gear pair. Journal of Vibration and Control, vol. 26, no. 19-20, p. 1721-1734, DOI:10.1177/1077546320902543. 